\title{
Review of Soil Water Retention Characteristic (SWRC) Models between Saturation and Oven Dryness
}

\author{
Vitalis K. Too*, Christian T. Omuto, Elijah K. Biamah, John P. Obiero \\ Department of Environmental and Biosystems Engineering, University of Nairobi, Nairobi, Kenya \\ Email: vitalistoo@yahoo.co.uk
}

Received 15 August 2014; revised 16 September 2014; accepted 15 October 2014

Copyright (C) 2014 by authors and Scientific Research Publishing Inc.

This work is licensed under the Creative Commons Attribution International License (CC BY).

http://creativecommons.org/licenses/by/4.0/

c) (i) Open Access

\begin{abstract}
Soil water retention characteristic is the key soil property used in many applications in the fields of irrigation, hydrology, geotechnical engineering and soil science in general. Since the advent of digital soil mapping and digital soil assessment paradigms, there has been an upsurge of development of soil inference models and the need to increase accurate application of soil mapping products. All soils can be partially saturated with water and also near oven dryness. Therefore, constitutive models for soils should ideally represent the soil behaviour over entire range. This paper reviewed commonly used SWRC models. In order to stem potential for biasness, the models were grouped into three categories depending on the number of fitting parameters, namely, fiveparameter, four-parameter and three-parameter categories. The evaluation used correlation and residual standard error statistics to choose the best overall performing model and in each category. Its results serve as a guide for selecting the models to be preferred for fitting SWRC in case there are limitations to the number of suction potential levels in the measured data.
\end{abstract}

\section{Keywords}

Water Retention, Hydraulic Parameters, Models

\section{Introduction}

Soil water characteristic is the key soil property used in many applications in the fields of irrigation, hydrology, geotechnical engineering and soil science in general. Soil water characteristic influences many physical and engineering characteristics which are key soil properties for appropriate management of the soil degradation, water

"Corresponding author.

How to cite this paper: Too, V.K., Omuto, C.T., Biamah, E.K. and Obiero, J.P. (2014) Review of Soil Water Retention Characteristic (SWRC) Models between Saturation and Oven Dryness. Open Journal of Modern Hydrology, 4, $173-182$.

http://dx.doi.org/10.4236/ojmh.2014.44017 
resources and environment. Water content in the soil is held by two principal forces: adsorption and capillarity. Adsorption is responsible for moisture held on the surface of soil particles while capillarity holds water in the pores between the soil particles or between aggregates of the particles [1]. The relationship between combined effect of these forces (also often expressed in the form of potential head) and soil water content forms a basic property of soil referred to as the Soil Water Retention Characteristics (SWRC) [2]. Typically, soils exhibit large variations in space and occasionally in time as well. Consequently, soil water retention characteristics models have been developed that allow a physical description of soil properties with the least amount of effort.

Some of the commonly used analytical models of SWRC in the literature are Brooks-Corey, Farrell-Larson, Fredlund-Xing, Gardner, McKee-Bumb, Kosugi, van Genuchten, Campbell, Russo, Tani, Omuto, and Dexter models [3]-[5]. Many of these models have been reported successful only for certain parts of SWRC (e.g. wet or dry parts), soil textures, soil horizons, regions of the world, or limited soil stress history [6]. These models contain shape parameters known as hydraulic parameters. Applications of water retention models require knowing these hydraulic parameters. Soil hydraulic parameters are traditionally obtained by curve-fitting the water retention functions using experimental data [7].

Presently, there are many models in the literature and many more still being developed so much so that it is confusing about which model to prefer. The current choice of the appropriate model to use has not been well guided by any incisive research on the predictive performance of these models, especially between saturation and oven dryness. Consequently, SWRC model applications have been largely moved by convenience. It is worth noting that the difficulties of soil characterization increase when soil approaches oven dryness conditions a situation often encountered in arid and semi-arid areas. The cost of establishing the soil water characteristics can be relatively high in this area. The objective of this study was to review SWRC models between saturation and oven dryness so as to establish their performance and to recommend the most suitable models to be used in a given range.

\section{Theory}

\subsection{Features of Soil Water Retention Characteristics}

Soil water retention characteristic is the relationship between amount of water held in the soil and the forces holding it. The graph giving the relation between soil water tension and soil water content is called water retention curve or soil water characteristic. If the tension is expressed as the logarithmic value of $\mathrm{cm}$ water, the graph is referred to as a $\mathrm{pF}$-curve. Water retention curves are used:

1) To determine an index of the available water in soil and to classify soils accordingly, e.g. for irrigation purposes, construction etc.;

2) To determine the drainable pore space (effective pore space, effective porosity, specific yield) for drainage design;

3) To check changes in the structure of a soil, e.g. caused by tillage, mixing of soil layers etc.;

4) To ascertain the relation between soil water tension and other physical properties of soil (e.g. capillary conductivity, thermal conductivity, clay and organic matter content).

The maximum amount of moisture that can be held in the soil pores is denoted by the SWRC models as saturated moisture content, $\theta_{s}$. A point $h_{a}$ in the models where air begins to enter the soil pores (during drainage) or where all air is expelled (during wetting) is known as the air-entry potential (Figure 1). $h_{a}$ and $\theta_{s}$ are soil hydraulic properties describing the shape of the wet-end of SWRC curves. Between $h_{a}$ and the point of complete dryness, the rate of moisture release or entry in the soil is fast or slow depending on the range of pore sizes in the soil matrix, assuming that other factors such as stress history are constant [1] [5]. For example, with narrow pore-size distribution such as in sandy soil the rate is fast (and hence the part of WRC curve between $h_{a}$ and point of complete dryness has a steep slope) and in broad pore-size distribution such as in clay soil the rate is slow (and WRC curve between $h_{a}$ and point of complete dryness has a gentle slope). The rate of moisture release is very slow towards the end of a completely dry soil; thus, the slope is very gentle for this section of WRC. The slope of the dry section of SWRC intersects the slope of the section after $h_{a}$ at a point where the corresponding moisture content is known as residual moisture content $\left(\theta_{r}\right)$ [5] [8] [9] (Figure 1).

\subsection{SWRC Models}

Quite a number of SWRC models have been proposed over the years to describe the soil water retention charac- 


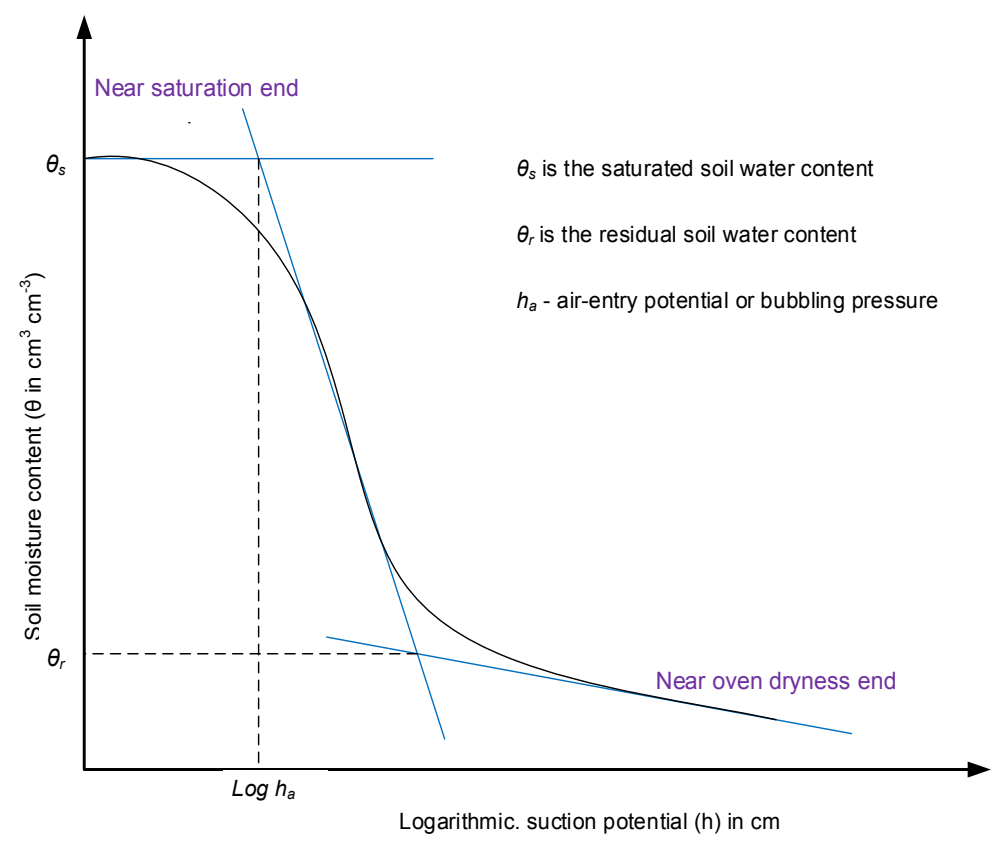

Figure 1. Soil water characteristic curve.

teristic across the complete range of soil water contents. Some of these models are new while others are modification of the existing models. Some of these models are discussed below.

\subsection{1. van Genuchten Water Retention Model}

A commonly used retention model is the van Genuchten [10] closed form analytical expression. The closed form equation consists of four independent parameters which have to be estimated from observed soil water retention data. Many curve fitting and parameter optimization codes such as RETC software [7] are widely used today. These types of relationships are empirical in nature with a physical basis. The van Genuchten [10] equation is expressed as:

$$
\theta(h)=\theta_{r}+\left(\theta_{s}-\theta_{r}\right)\left[1+(\alpha h)^{n}\right]^{-m}
$$

where, $\theta$ is the volumetric water content; $h$ is the pressure head; $\theta_{s}$ and $\theta_{r}$ represent the saturated and residual water contents, respectively; $\alpha, n$ and $m$ are empirical shape parameters.

\subsubsection{Brooks-Corey Water Retention Model}

Another well-established parametric model was proposed by Brooks and Corey [11]. This is a four-parameter water retention model. A Brooks-Corey model is a type of nonlinear curve fitting model for fitting water retention characteristics using experimental data. The Brooks-Corey functions can be defined as:

$$
\theta(h)=\theta_{r}+\left(\theta_{s}-\theta_{r}\right)(\alpha h)^{-\lambda}
$$

Where, $\theta_{r}$ is the residual water content $\left(\mathrm{cm}^{3} / \mathrm{cm}^{3}\right), \theta_{s}$ is the saturated water content $\left(\mathrm{cm}^{3} / \mathrm{cm}^{3}\right), h$ is the matric potential $(\mathrm{cm}), \lambda$ and $\alpha$ are empirical shape parameters.

\subsubsection{Fredlund-Xing Water Retention Model}

This is a five-parameter water retention model [8].

$$
\theta=\theta_{r}+\frac{\theta_{s}-\theta_{r}}{\left\{\ln \left[\mathrm{e}+(h / \alpha)^{n}\right]\right\}^{m}}
$$

where, $\theta_{r}$ is the residual water content $\left(\mathrm{cm}^{3} / \mathrm{cm}^{3}\right) ; \theta_{s}$ is the saturated water content $\left(\mathrm{cm}^{3} / \mathrm{cm}^{3}\right) ; h$ is the suction; 
cm, $\alpha, n$ and $m$ are empirical shape parameters.

The Fredlund-Xing water retention model was developed based on pore size distribution of the soil. If the pore size distribution of a soil can be obtained or predicted, then the soil water characteristic curve is uniquely determined from the equation above.

\subsubsection{Gardner Water Retention Model}

This is a four-parameter water retention model by Gardner.

$$
\theta(h)=\theta_{r}+\left(\theta_{s}-\theta_{r}\right)\left[1+(\alpha h)^{n}\right]^{-1}
$$

\subsubsection{Biexponential Water Retention Model}

Biexponential water retention model was developed by Omuto. This is a five-parameter water retention model contained in a bimodal pore-size distribution. The parameters are for the first and second compartments [5].

$$
\theta(h)=\theta_{r}+\theta_{1} \mathrm{e}^{-\alpha_{1} h}+\theta_{2} \mathrm{e}^{-\alpha_{2} h}
$$

where, $\theta_{1}$ represents the difference between saturated moisture $\left(\theta_{s 1}\right)$ and residual moisture contents $\theta_{r 1}$ in the structural pore-space; $\theta_{2}$ represents the difference between saturated moisture $\left(\theta_{s 2}\right)$ and residual moisture contents $\theta_{r 2}$ in the textural pore-space; $\alpha_{1}$ represents the inverse of air-entry potential in the structural pore-space; $\alpha_{2}$ represents the inverse of air-entry potential in the soil textural pore-space; $\theta_{r}$ is the sum of residual moisture contents in the structural pore-space $\left(\theta_{r 1}\right)$ and textural pore-space $\left(\theta_{r 2}\right)$.

\subsubsection{Campbell Water Retention Model}

This is a three-parameter water retention model [5].

$$
\theta(h)=\theta_{s}(\alpha h)^{\lambda}
$$

where, $h$ is suction potential/head; $\theta_{s}$ is the saturated moisture content. It's the moisture content when suction potential is very low (almost at the saturation point); $\alpha$ is the inverse of $h_{a}$ air-entry potential or bubbling pressure, $\lambda$ is a parameter or index for the pore-size distribution.

\subsubsection{Tani Water Retention Model}

This is a three-parameter water retention model developed by Tani in 1982 [5].

$$
\theta=\theta_{r}+\left(\theta_{s}-\theta_{r}\right)\left[1+(\alpha h) \mathrm{e}^{-\alpha h}\right]
$$

where, $h$ Suction potential/head; $\theta_{r}$ is the residual moisture content. It's the moisture content when suction potential is very high (almost at the drying point); $\theta_{s}$ is the saturated moisture content. It's the moisture content when suction potential is very low (almost at the saturation point); $\alpha$ is the inverse of air-entry potential or bubbling pressure.

\subsubsection{Kosugi Water Retention Model}

This is a four-parameter water retention model developed by Kosugi in 1999 [5].

$$
\theta(h)=\theta_{r}+\frac{1}{2}\left(\theta_{s}-\theta_{r}\right) \operatorname{erfc}\left[\frac{\ln \left(h / h_{m}\right)}{\sigma \sqrt{2}}\right]
$$

where, $\theta_{s}$ is the saturated soil water content; $\theta_{r}$ is the residual soil water content; $h_{m}$ is the matric potential corresponding to the median pore radius; $\sigma$ is a dimensionless parameter to characterize the width of the pore-size distribution; $\operatorname{erfc}$ denotes the complementary error function.

\subsubsection{Ruso Water Retention Model}

Ruso water retention model is a four-parameter function. This is a type of nonlinear curve fitting model for fitting water retention characteristics using experimental data [12].

$$
\theta(h)=\theta_{r}+\left(\theta_{s}-\theta_{r}\right)\left[(1+0.5 \alpha h) \mathrm{e}^{0.5 \alpha h}\right]^{2 / n+2}
$$


where, $h$ is suction potential/head as contained in the x-column of the xy water retention table or data; $\theta_{r}$ is the residual moisture content. It's the moisture content when suction potential is very high (almost at the drying point); $\theta_{s}$ is the saturated moisture content. It's the moisture content when suction potential is very low (almost at the saturation point); $\alpha$ is the inverse of air-entry potential or bubbling pressure; $n$ is a parameter or index for the pore-size distribution.

\subsubsection{Exponential Model}

This is a three-parameter water retention model [12].

$$
\theta(h)=\left(\theta_{r}+\theta_{s}\right) \mathrm{e}^{-\alpha h}
$$

where, $h$ is suction potential/head as contained in the $\mathrm{x}$-column of the xy water retention table or data; $\theta_{r}$ is the residual moisture content; $\theta_{s}$ is the saturated moisture content; $\alpha$ is the inverse of air-entry potential or bubbling pressure (Table 1).

\section{Data Sources}

Water retention data used were downloaded from the ISRIC database on May 62013 and locally obtained data from Athi River (Kenya). The data contained soil water content $\left(\theta\right.$ in $\left.\mathrm{cm}^{3} \mathrm{~cm}^{-3}\right)$ at various levels of suction potential $(h)$ in $\mathrm{cm}$ (Figure 2(a) and Figure 2(b)).

The global datasets were further split into samples from Central America, South America, Africa, Europe, Middle East, North Asia and South Asia (Figure 2(c)).

\section{Performance of SWRC Models Using a Test Data}

The models' performance was assessed based on their accuracy and prediction potential between saturation and oven dryness.

The best performance of each SWRC model was the one which gave the minimum Residual Standard Error, RSE and a correlation, $\mathrm{R}^{2}$ close to unity. The following popular statistics were used:

\section{Table 1. SWRC models.}

\begin{tabular}{ccc}
\hline Reference & SWRC model & Parameters \\
\hline Campbell (1974) & $\theta(h)=\theta_{s}(\alpha h)^{\lambda}$ & $\theta_{s}, \alpha, \lambda$ \\
Tani (1982) & $\theta(h)=\theta_{r}+\left(\theta_{s}-\theta_{r}\right)\left[1+(\alpha h) \mathrm{e}^{-\alpha h}\right]$ & $\theta_{r}, \theta_{s}, \alpha$, \\
Exponential & $\theta(h)=\left(\theta_{r}+\theta_{s}\right) \mathrm{e}^{-\alpha h}$ & $\theta_{r}, \theta_{s}, \alpha$, \\
van Genuchten (1980) & $\theta(h)=\theta_{r}+\left(\theta_{s}-\theta_{r}\right)\left[1+(\alpha h)^{n}\right]^{-\left(1-\frac{1}{n}\right)}$ & $\theta_{r}, \theta_{s}, \alpha, n$ \\
Gardner (1958) & $\theta(h)=\theta_{r}+\left(\theta_{s}-\theta_{r}\right)\left[1+(\alpha h)^{n}\right]^{-1}$ & $\theta_{r}, \theta_{s}, \alpha, n$ \\
Ruso & $\theta(h)=\theta_{r}+\left(\theta_{s}-\theta_{r}\right)\left[(1+0.5 \alpha h) \mathrm{e}^{0.5 \alpha h}\right]^{2 / n+2}$ & $\theta_{r}, \theta_{s}, \alpha, n$ \\
Brooks-Corey (1964) & $\theta(h)=\theta_{r}+\left(\theta_{s}-\theta_{r}\right)(\alpha h)^{-\lambda}$ \\
Kosugi (1999) & $\theta(h)=\theta_{r}+\frac{1}{2}\left(\theta_{s}-\theta_{r}\right) \operatorname{erfc}\left[\frac{\ln \left(h / h_{m}\right)}{\sigma \sqrt{2}}\right]$ \\
Bredlund-Xing (1994) & $\theta(h)=\theta_{r}+\frac{\theta_{s}-\theta_{r}}{\left\{\ln \left[2.7183+(\alpha h)^{n}\right]\right\}^{m}}$ \\
van Genuchten (1980) & $\theta(h)=\theta_{r}+\left(\theta_{s}-\theta_{r}\right)\left[1+(\alpha h)^{n}\right]^{-m}$ \\
Biexponential (Omuto, 2009) & $\theta_{r}+\theta_{s 1} \mathrm{e}^{-\alpha_{1} h}+\theta_{s 2} \mathrm{e}^{-\alpha_{2} h}$ & $\theta_{r}, \theta_{s}, \sigma, h_{m}$ \\
& $\theta_{r}, \theta_{s}, \alpha, n, m$
\end{tabular}




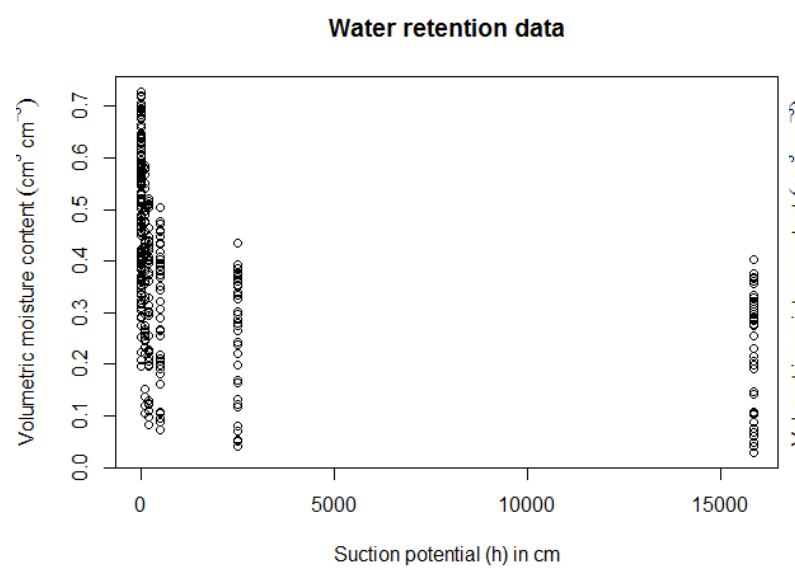

(a)

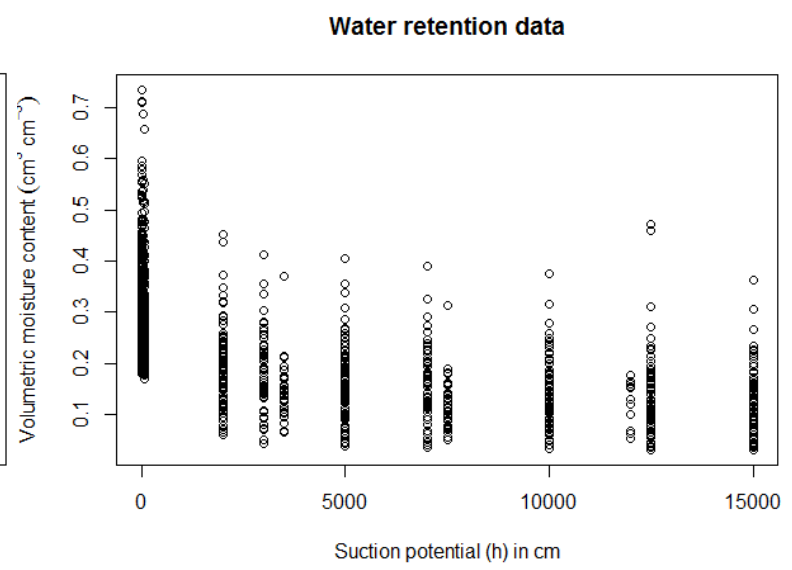

(b)

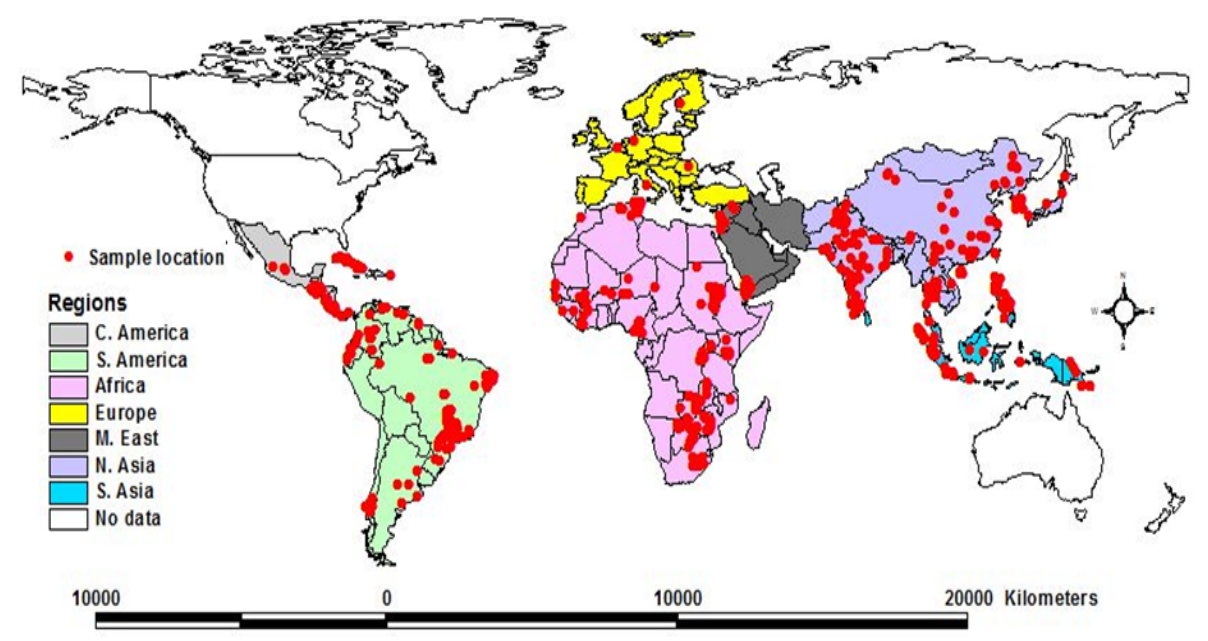

(c)

Figure 2. (a) Water retention data from Isric global data base; (b) Water retention data from Athi River, Kenya; (c) Spatial distribution of data samples.

1) Residual standard error, RSE

$$
\sum_{i=1}^{n}\left(y_{i}-\hat{y}_{i}\right)^{2} /(n-2)
$$

2) Correlation, $R^{2}$

$$
\left(n \sum_{i=1}^{n} y_{i} \hat{y}_{i}-\left(\sum y_{i}\right)\left(\sum \hat{y}_{i}\right)\right)^{2} /\left[\left(n\left(\sum y_{i}^{2}\right)-\left(\sum y\right)^{2}\right)-\left(n\left(\sum \hat{y}_{i}^{2}\right)-\left(\sum \hat{y}_{i}\right)^{2}\right)\right]
$$

The SWRC models were grouped based on the number of fitting parameters as shown in Table 2. All the models were fitted using ISRIC global dataset and locally obtained data from Athi River (Kenya) using Hydro $\mathrm{Me}, \mathrm{R}$ computer program. The performance of the models were reviewed based on the Residual Standard Error (RSE) and correlation coefficient $\left(\mathrm{R}^{2}\right)$ in the entire soil range and also at near saturation to oven dryness.

Several attempts have been made to derive models for the purpose of analyzing the soil water characteristics in the entire range between saturation and near oven dryness. Some models have proved to perform poorly in near saturation and others in near oven dryness. This study analyzed the performance of 10 SWRC models on their performance in the entire soil range, near saturation and near oven dryness.

\subsection{Between Saturation and Oven Dryness}

Table 2 shows that Biexponential model (Omuto, 2009) had the best performance statistics for the category 
Table 2. Performance of SWRC models.

\begin{tabular}{|c|c|c|c|c|c|c|}
\hline \multirow[t]{2}{*}{ Reference } & \multicolumn{2}{|c|}{ Overall } & \multicolumn{2}{|c|}{ Near saturation } & \multicolumn{2}{|c|}{ Near oven dryness } \\
\hline & RSE & $\mathrm{R}^{2}$ & RSE & $\mathrm{R}^{2}$ & RSE & $\mathrm{R}^{2}$ \\
\hline \multicolumn{7}{|c|}{ Three-parameter models } \\
\hline Campbell (1974) & 0.08134 & 0.5246984 & 0.007665 & 0.8796749 & 0.003703 & 0.9788181 \\
\hline Tani (1982) & 0.07873 & 0.5661897 & 0.004983 & 0.9509574 & 0.004749 & 0.9648825 \\
\hline Exponential & 0.07792 & 0.5783668 & 0.003783 & 0.9720321 & 0.003793 & 0.9777493 \\
\hline \multicolumn{7}{|c|}{ Four-parameter models } \\
\hline Gardner (1958) & 0.016564 & 0.9893501 & 0.002568 & 0.991553 & 0.009743 & 0.9905466 \\
\hline Ruso (1998) & 0.07796 & 0.577969 & 0.004351 & 0.9703861 & 0.00445 & 0.9770206 \\
\hline Brooks-Corey(1964) & 0.07991 & 0.548148 & 0.008066 & 0.8941245 & 0.003813 & 0.9831745 \\
\hline Kosugi (1999) & 0.07988 & 0.5486333 & 0.002266 & 0.9920582 & 0.003795 & 0.9833413 \\
\hline \multicolumn{7}{|c|}{ Five-parameter models } \\
\hline Fredlund-Xing (1994) & 0.07703 & 0.5919019 & 0.002646 & 0.9918761 & 0.003523 & 0.9904626 \\
\hline van Genuchten (1980) & 0.07705 & 0.5914976 & 0.002568 & 0.992349 & 0.004789 & 0.9823130 \\
\hline Biexponential (Omuto, 2009) & 0.017174 & 0.9885479 & 0.002463 & 0.9906058 & 0.002447 & 0.9931029 \\
\hline
\end{tabular}

with five-parameter models. The Gardner (1958) model had the best performance statistics in the four-parameter models category and the Exponential model had the best performance statistics in the three-parameter categories.

Review of these SWRC model performances in the entire soil range indicated that Gardner (1958) and Biexponential model had the highest $\mathrm{R}^{2}$ value (Figure 3 ) compared to all other tested models. Generally, five-parameter models predicted the measured SWRC better than the others in the entire soil range. This could be true because many parameters tend to pin the model as close to the inflection points and end-points of the SWRC as possible. Hence, they allow the models to pass closest to the measured data compared to models with few parameters.

\subsection{Near Saturation}

As shown in Table 2, van Genuchten (1980) model had the highest statistical value in the five-parameter category while Kosugi (1999) model performed better in the four-parameter category. Exponential model also performed best in the three-parameter category. Generally, the van Genuchten model predicts soil water characteristic more accurately on near saturation as compared to other SWRC models.

In Figure 4(a), the soil $\theta(h)$ curve expressed by Equation (1) (van Genuchten) does not account for the bubbling pressure but does have an inflection point, allowing the van Genuchten model to perform better than other models (for example Brooks and Corey) at near saturation soil range (Figure 4(b)).

It is worth noting that Equations (1) and (2) have considerable difficulty in representing the retention of water near oven dryness (matric suction at $15000 \mathrm{~cm}$ - permanent wilting point) giving an unrealistic path of the retention curve. van Genuchten and Brooks and Corey models does well when applied in wetland studies or humid region agriculture but for applications such as water flow in arid and semi-arid areas require a realistic representation for hydraulic characteristics over the all range of saturation.

\subsection{Near Oven Dryness}

Further analysis of the SWRC models' performance near oven dryness showed that Campbell (1974) performed well in the three-parameter category (Table 2). According to Omuto (2009), anchoring the SWRC at the endpoints tends to improve the model performance. This is contrasted by the performance of the Campbell (1974) model in near oven dryness range as shown in Figure 5(a) and Figure 5(b). The model performed best compared to its competitors in the three-parameter model category. The study proved right the argument by some authors that elimination of the residual moisture content $\left(\theta_{r}\right)$ can improve the predictive performance (see for example, [8]).

Gardner (1958) and Biexponential models outperformed the other models in their respective categories. In 


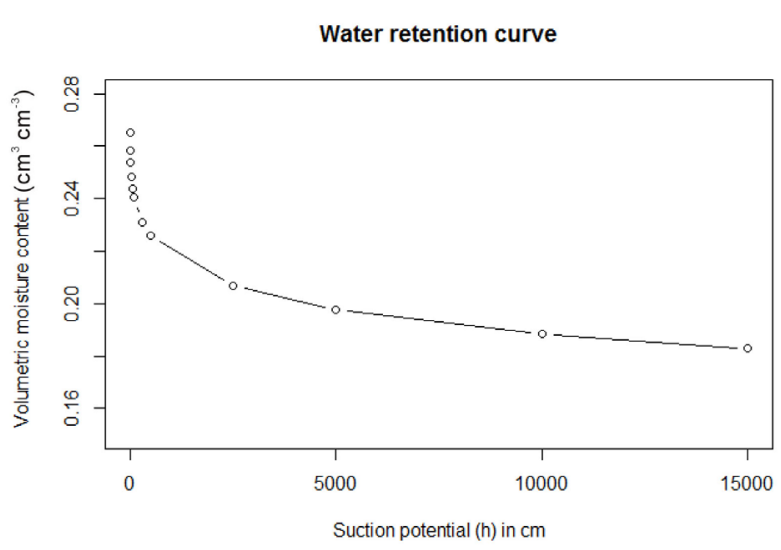

(a)

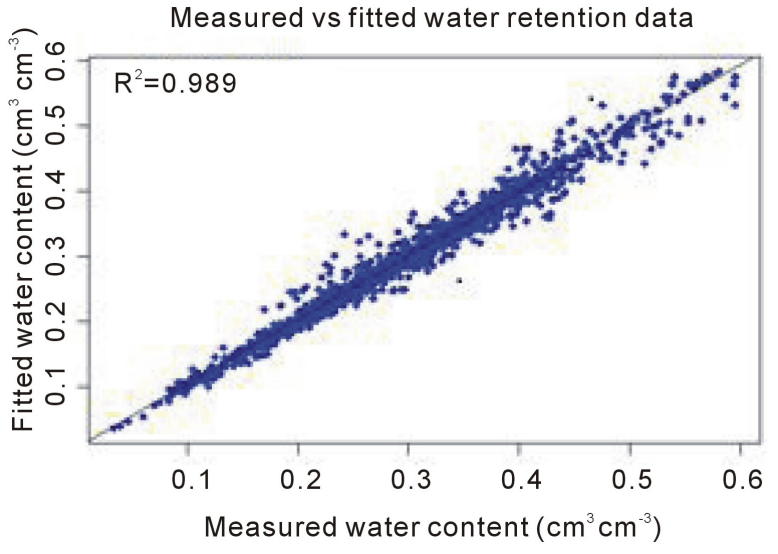

(b)

Figure 3. Gardner (1958) SWRC model.

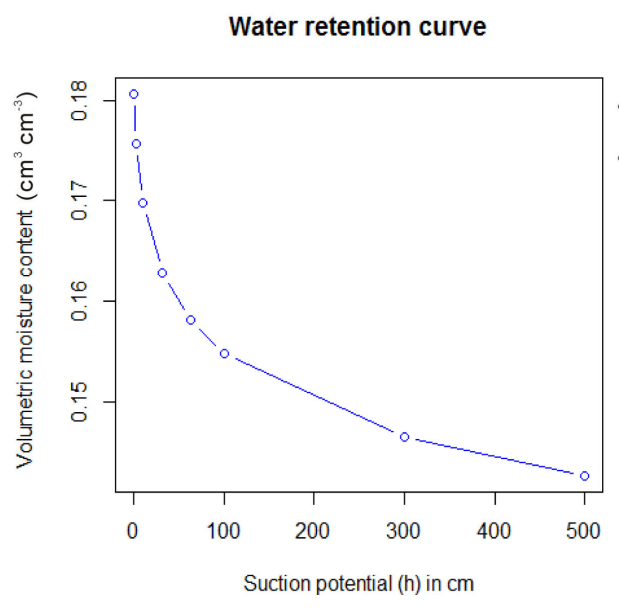

(a)

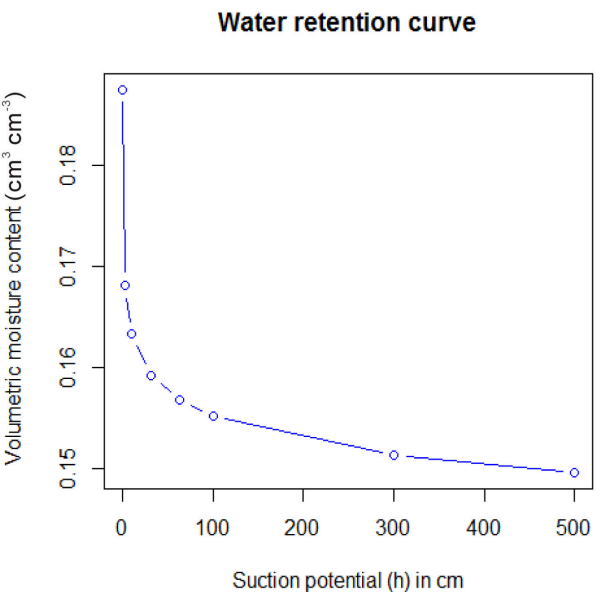

(b)

Figure 4. (a) van Genuchten model curve; (b) Brooks and Corey model curve.

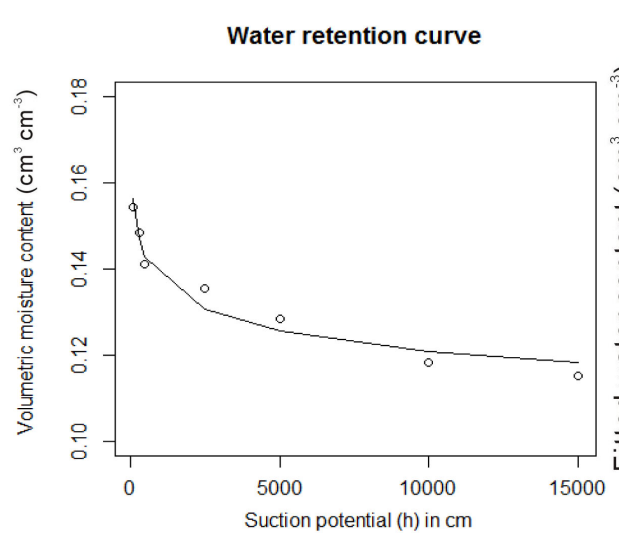

(a)

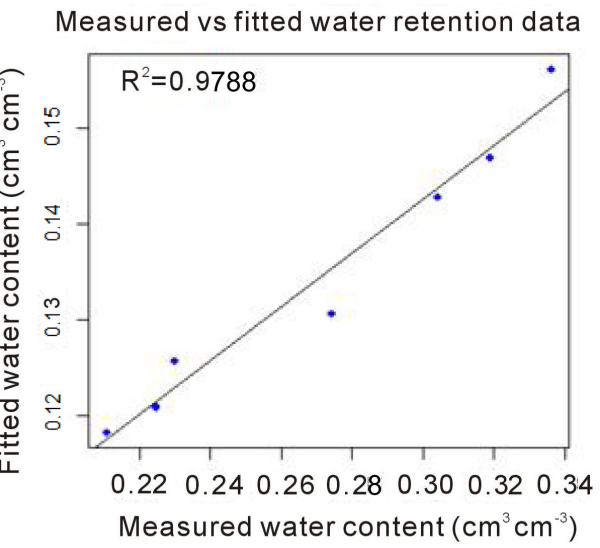

(b)

\section{Figure 5. (a) Campbell SWRC model curve; (b) Measured vs fitted SWRC data.}

overall, Biexponential model was the best model in this soil range.

It is worth noting that Biexponential model showed a lot of consistency in the three soil categories (overall, 
near saturation and oven dryness) by having the best fit. These results show that the model is capable of fitting the entire range of SWRC without numerical discontinuities that have been reported in other models [13]. The performance can be explained by the fact that this model is a bi-compartment model (Equation (5)) that assumes two pore-size distribution functions for the soil pores, i.e. for structural pore space and for the textural pore space unlike most SWRC models in the literature which ignore the structural pore spaces resulting in inadequate representation of the true soil water retention characteristics for field condition yet the soil pore architecture in field conditions comprises of both the textural and structural pore spaces.

\section{Conclusions}

It was observed that all five-parameter models performed much better than the four- and three-parameter models. Among the five-parameter models, Biexponential model (Omuto, 2009) performed better than the van Genuchten (1980), and Fredlund and Xing (1994). In the four-parameter category, Gardner (1958) performed better than Brooks and Corey (1964), Kosugi (1999) and Ruso (1998). Among the three-parameter category, Exponential model performed better than Campbell (1974) and Tani (1982).

In overall, Biexponential model performed better than other models. This is because the model is a bi-compartment model that assumes two pore-size distribution functions for the soil pores, i.e. for structural pore space and for the textural pore space unlike most SWRC models reviewed which ignore the structural pore spaces resulting in inadequate representation of the true soil water retention characteristics for field condition. Yet, the soil pore architecture in field conditions comprises of both the textural and structural pore spaces. Owing to the good performance of this model, the review also floats a suggestion for future models to develop models based on two pore-size distribution functions for the soil pores.

\section{Acknowledgements}

The soil data used in this study were obtained from The International Soil Reference and Information Centre (ISRIC). The organization and countries which contributed to this dataset are highly acknowledged.

\section{References}

[1] Marshall, T.J., Holmes, J.W. and Rose, W.C. (1996) Soil Physics. Cambridge University Press, London. http://dx.doi.org/10.1017/CBO9781139170673

[2] Omuto, C.T. and Gumbe, L.O. (2009) Estimating Water Infiltration and Retention Characteristics Using a Computer Program in R. Computers and Geosciences, 35, 579-585. http://dx.doi.org/10.1016/j.cageo.2008.08.011

[3] Leong, E.C. and Rahardjo, H. (1997) Review of Water Characteristic Curve Functions. Geotechnical and Geo-Environmental Engineering, 123, 1106-1117. http://dx.doi.org/10.1061/(ASCE)1090-0241(1997)123:12(1106)

[4] Dexter, A.R., Czyz, E.A., Richard, G. and Reszkowska, A. (2008) A User-Friendly Water Retention That Takes Account of the Textural and Structural Pore Spaces in Soil. Geoderma, 143, 243-253. http://dx.doi.org/10.1016/j.geoderma.2007.11.010

[5] Omuto, C.T. (2009) Biexponential Model for Water Retention Characteristics. Geoderma, 149, 235-242. http://dx.doi.org/10.1016/j.geoderma.2008.12.001

[6] Khlosi, M., Wim, M.C., Ahmed, D., Martinus, T. and Donald, G. (2008) Performance Evaluation of Models That Describe the Soil Water Retention Curve between Saturation and Oven Dryness. Vadose Zone Journal, 7, 87-96. http://dx.doi.org/10.2136/vzj2007.0099

[7] van Genuchten, M.T., Leij, F.J. and Yates, S.R. (1991)The RETC Code for Quantifying the Hydraulic Functions of Unsaturated Soils. EPA Report, 600/2-91/065, USA Salinity Laboratory, USDA.

[8] Fredlung, D.G. and Xing, A. (1994) Equations for the Soil Water Characteristic Curve. Canadian Geotechnical Journal, 31, 521-532. http://dx.doi.org/10.1139/t94-061

[9] Vanapalli, S.K., Sillers, W.S. and Fredlund, M.D. (1998) The Meaning and Relevance of Residual State to Unsaturated Soils. 51st Canadian Geotechnical Conference, Edmonton, 4-7 October 1998, 1-8.

[10] van Genuchten, M.T. (1980) A Closed-Form Equation for Predicting the Hydraulic Conductivity of Unsaturated Soils. Soil Science Society of America Journal, 44, 892-898. http://dx.doi.org/10.2136/sssaj1980.03615995004400050002x

[11] Brooks, R.H. and Corey, A.T. (1964) Hydraulic Properties of Porous Media. Hydrology Paper, Vol. 3, Colorado State University, Fort Collins.

[12] Omuto, C.T. (2007) HydroMe: Estimation of Soil Hydraulic Parameters from Experimental Data. R Comprehensive R 
Archive Network, USA.

[13] Vogel, T., van Genuchten, M.T. and Cislerova, M. (2001) Effect of the Shape of the Soil Hydraulic Functions near Saturation on Variably Saturated Flow Predictions. Advances in Water Resources, 24, 133-144.

http://dx.doi.org/10.1016/S0309-1708(00)00037-3 
Scientific Research Publishing (SCIRP) is one of the largest Open Access journal publishers. It is currently publishing more than 200 open access, online, peer-reviewed journals covering a wide range of academic disciplines. SCIRP serves the worldwide academic communities and contributes to the progress and application of science with its publication.

Other selected journals from SCIRP are listed as below. Submit your manuscript to us via either submit@scirp.org or Online Submission Portal.
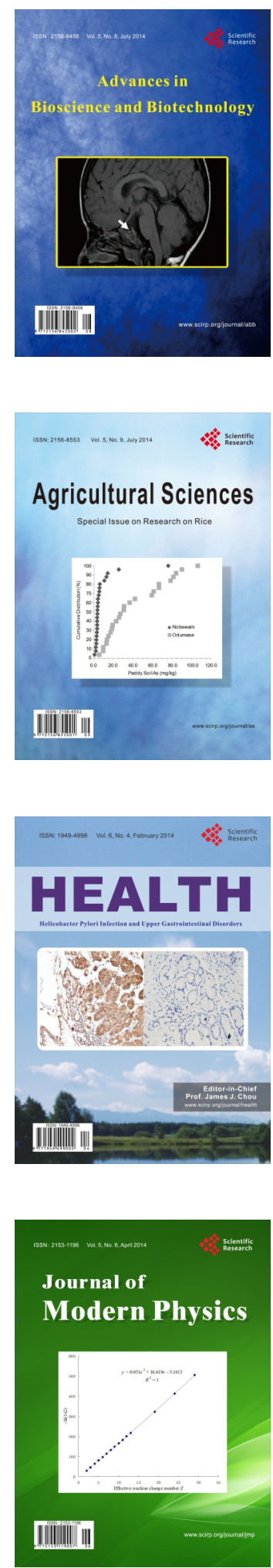
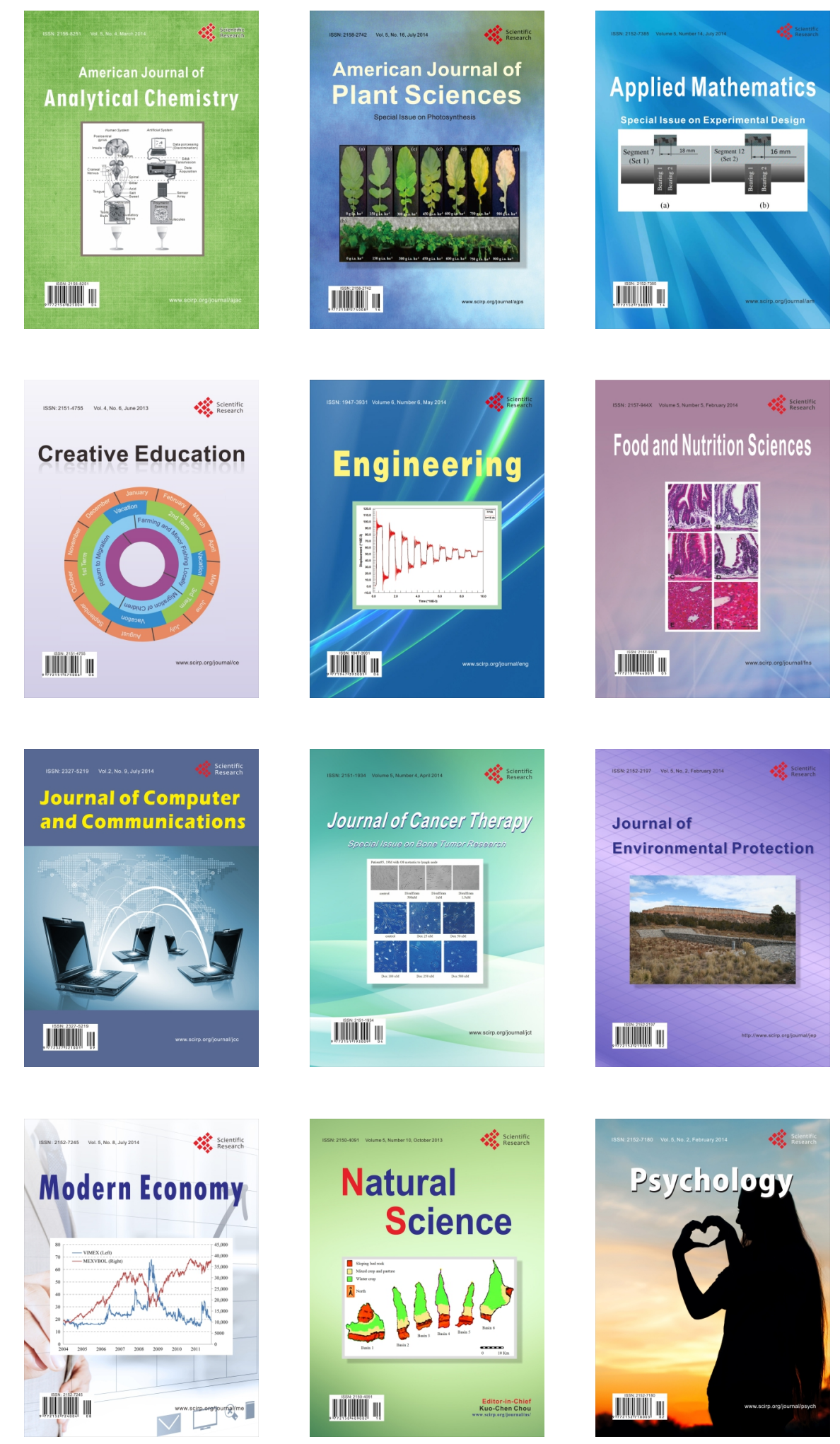